\title{
Critérios de avaliação para sistemas de bibliotecas digitais: uma proposta de novas dimensões analíticas
}

\author{
Evaluation criteria for digital library systems: a proposal for new analytical dimensions
}

\begin{abstract}
Dalton Lopes Martins
Doutor em Ciência da Informação pela ECA/Universidade de São Paulo - USP. Professor no curso de Gestão da Informação e no Programa de Pós-graduação da Faculdade de Informação e Comunicação da Universidade Federal de Goiás - UFG. E-mail: $\underline{\text { dmartins@gmail.com }}$

Marcel Ferrante Silva Doutor em Ciência da Informação pela Universidade Federal de Minas Gerais - UFMG. Professor Adjunto no Curso de Gestão da Informação da Faculdade de Informação e Comunicação da Universidade de Goiás - UFG. E-mail: marcelf@gmail.com
\end{abstract}

\section{Resumo}

O artigo apresenta uma revisão dos principais critérios utilizados pela literatura técnica na área da Ciência da Informação para análise e comparação de sistemas de informação voltados para a criação de bibliotecas digitais. Aponta as características desses critérios, procurando detalhar suas dimensões analíticas, potenciais e limitações. A partir dessa revisão, o artigo propõe um conjunto de dimensões analíticas inspiradas na Arquitetura da Informação para organizar e complementar esses critérios de comparação de sistemas. Sugere também algumas novas dimensões analíticas oriundas dos novos paradigmas de interação da websocial e conclui propondo um conjunto integrado de critérios organizados por dimensões que deveriam ser levados em consideração quando da comparação e análise de sistemas de informação de bibliotecas digitais.

Palavas-chave: Bibliotecas digitais. Dimensões analíticas. Critérios de comparação. Websocial.

\begin{abstract}
The article presents an overview of the main criteria used by the technical literature in the area of Information Science for analysis and comparison of digital libraries information systems. Points out the features of these criteria, seeking to detail their analytical dimensions, potential and limitations. From this review, the paper proposes a set of analytical dimensions inspired by the Information Architecture theory to organize and complement these systems comparison criteria. It suggests some new analytic dimensions derived from the new social web interaction paradigms and concludes by proposing an integrated set of criteria organized by dimensions that should be taken into account when comparing and analyzing information of digital library systems.
\end{abstract}

Keywords: Digital libraries. Analytical dimensions. Benchmarks. Social web.

InCID: R. Ci. Inf. e Doc., Ribeirão Preto, v. 8, n. 1, p. 100-121, mar./ago. 2017.

DOI: $10.11606 /$ issn.2178-2075.v8i1p100-121 


\title{
1. Introdução
}

O conceito e os modos de produção de bibliotecas digitais é algo que tem ganho grande relevância na pesquisa e na criação de projetos voltados para diferentes públicos como maneira de organizar acervos e ofertar acesso a conteúdos digitalizados como complemento aos modos tradicionais de acesso a conteúdos físicos. Diversas políticas públicas, mesmo que ainda de forma incipiente, têm sido sensíveis a questão das bibliotecas digitais e apostado na produção de políticas integradas, tais como a iniciativa do Ministério da Cultura na criação de uma Política Nacional de Acervos Digitais (MINISTÉRIO DA CULTURA, 2015).

Muito se tem falado sobre a importância dessa estratégia como modo de democratização do acesso a informação, como possibilidade de ampliação do potencial de acesso e difusão de acervos que ficariam tradicionalmente restritos a condições logísticas de acesso e visitação e como um paradigma informacional que permite a produção novos tipos de serviços de informação ampliando o potencial de inovação e criação de novos modos de atuação. Além disso, novas possibilidades de interação social derivadas de novas tecnologias da Internet parecem permitir a criação de novas formas de experimentação e socialização na forma de organizar o trabalho informacional envolvido na criação dessas bibliotecas.

Segundo Sayão (2008-2009),

\begin{abstract}
As bibliotecas digitais surgem num contexto que sobrepõe, por um lado, a integração e uso das tecnologias de informação e de comunicação, das redes de computadores, das tecnologias de apresentação e o barateamento dos meios de armazenamento em massa; e, por outro, a disponibilidade crescente de conteúdos digitais em escala planetária, a possibilidade de digitalização a um custo economicamente viável de conteúdos em mídias convencionais e, ainda, o fenômeno conhecido como coerência das mídias digitais, que abre a possibilidade singular para a concepção de novos serviços de informação a partir da integração de objetos digitais heterogêneos.
\end{abstract}

De fato, uma junção de fatores técnicos e sociais parecem convergir no fortalecimento do conceito de bibliotecas digitais como meio que favorece a convergência entre a disponibilização de conteúdos informacionais e a possibilidade de produção de diferentes e novos modos de relacionamento social na produção e uso desses conteúdos.

No entanto, como um elemento estratégico de grande importância na concepção de uma biblioteca digital se encontra a necessidade de projetar funcionalidades, formas de interação, modos de organização da informação e funcionamento do fluxo informacional que atenda às expectativas 
tanto dos gestores desse serviço quanto de sua potencial comunidade de usuários. Torna-se, portanto, um desafio entender como traduzir as demandas de gestão e funcionamento do serviço em funcionalidades técnicas que devem ser atendidas por um sistema de informação customizado para tal. Moreno (2009) explicita esse desafio ressaltando algumas dimensões que deveriam ser levadas em consideração para a escolha de uma ferramenta:

O desafio das instituições de documentação é, justamente, o de filtrar, do conjunto de ferramentas disponíveis no mercado e nos centros de produção acadêmica, aquelas que possibilitem o desenvolvimento de uma proposta conceitual de instrumento de divulgação que garanta tanto a disseminação da informação como a preservação dessa informação a partir dos meios em que foi gerada. Essa foi sempre a missão enfrentada por bibliotecas e arquivos que, hoje, vivenciam no ambiente virtual a atualização da confusão constantemente enfrentada no meio físico, criada pela geração incontrolável de registros do conhecimento.

Dessa maneira, o objetivo da presente pesquisa é produzir uma síntese funcional e sugerir uma forma de aplicar critérios de avaliação para a escolha de uma ferramenta de apoio a produção de uma biblioteca digital. Para tanto, apresentamos ao longo deste trabalho um mapeamento de critérios de avaliação que tem sido utilizado por pesquisadores da área, procurando ressaltar a divergência de abordagens bem como suas especificidades. Na sequência, apresentamos algumas contribuições de conceitos e nomenclatura da área de Arquitetura da Informação como subsídio para a proposição de dimensões analíticas como forma de organização dos critérios de avaliação. Por fim, apresentamos uma síntese de critérios de avaliação sistematizados por dimensões e uma sugestão de formas de aplicação desses critérios para avaliação.

Acreditamos que a construção de iniciativas que visam integrar critérios de avaliação e criar repertórios analíticos sistematizados pode fornecer importantes contribuições para a pesquisa na área de bibliotecas digitais, sobretudo por fornecer vocabulários comuns que podem, se adotados por diferentes grupos de pesquisadores, servir como formas de comparação de diferentes ferramentas e facilitar a escolha e adoção de diferentes tecnologias que atendam melhor as necessidades dos profissionais de informação na realização de seus projetos. Logo, a construção de um modelo de critérios de avaliação é motivada por: 1) ajudar os profissionais de informação na escolha de uma ferramenta mais adequada para atender suas necessidades; 2) guiar os analistas de sistemas e profissionais da área de desenvolvimento de software no desenvolvimento de sistemas de bibliotecas digitais mais completos em funcionalidades e facilmente comparável com outros sistemas da área; e 3) possibilitar aos usuários utilizarem uma biblioteca digital que lhe 
atenda de forma mais satisfatória, estimulando-os para uma maior interação social e compartilhamento de seu conhecimento.

Apresentamos, a seguir, uma revisão das principais pesquisas encontradas que utilizam critérios de avaliação na comparação de ferramentas de bibliotecas digitais a partir dos procedimentos metodológicos descritos abaixo.

\section{Procedimentos metodológicos}

O foco para o mapeamento de estudos de referência sobre critérios de avaliação de bibliotecas digitais levou em consideração a utilização de chaves de busca com as palavras, em língua portuguesa e inglesa, "comparação", "lista de critérios", "software livre" e "biblioteca digital", sendo a pesquisa realizada nas bases de dados Web of Science, Portal de Periódicos da CAPES, Brapci e Google Acadêmico.

Vale frisar aqui que focamos esta pesquisa apenas em softwares livres, ou seja, aqueles que possuem seu código disponível para modificações e desenvolvimento de novas versões por comunidades de interesse. Entendemos que fortalecer a utilização desse tipo de software não apenas se torna mais economicamente viável para as instituições custodiais, considerando que o software é em sua maioria das vezes gratuito, como também permite o reaproveitamento de esforços e tecnologia no caso de novos desenvolvimentos e customização de funcionalidades que esses softwares eventualmente não atendam em sua versão padrão.

A pesquisa brasileira na área da Ciência da Informação envolvendo plataforma de softwares para bibliotecas digitais se mostra ainda bastante tímida, sendo que encontramos apenas 6 trabalhos na base de dados Brapci, especializada na área, para as chaves de pesquisa "biblioteca digital"+software e "bibliotecas digitais"+software. Discutiremos esses resultados a seguir.

Encontramos 07 estudos que consideramos relevantes e que serão as referências apresentadas a seguir sobre estudos comparativos considerando critérios de avaliação de bibliotecas. Todos os estudos encontrados se encontram em língua inglesa, ressaltando ainda mais a importância do desenvolvimento de pesquisas como esta, objetivando traduzir e sistematizar esses critérios de avaliação para a comunidade de pesquisares e usuários em língua portuguesa. 
Outra característica geral dos resultados encontrados é o fato de que dos 07 apenas um deles foi publicado antes de 2012, no caso no ano de 2006. Esse fator permite destacar também a novidade de pesquisas que procuram identificar critérios de avaliação para bibliotecas digitais e o que também pode ajudar a justificar a falta ainda de pesquisas nessa direção em língua portuguesa. Vamos agora a apresentação dos resultados encontrados.

\section{Bibliotecas digitais e plataformas de software}

A pesquisa brasileira na área da Ciência da Informação sobre plataformas de software envolvendo bibliotecas digitais ainda se mostra bastante tímida, com poucos artigos produzidos e, em sua maioria, se tratando de relatos de caso de aplicações de plataformas para a produção de experiências de criação e implementação de bibliotecas digitais.

Nos chamou a atenção o artigo de Plasencia-Salgueiro e Ballagas-Flores (2014) que analisaram 8 ferramentas de recuperação da informação para bibliotecas digitais dando ênfase específica em softwares livres. Apesar de referencia importante para o tema, o artigo foca na questão de dispositivos técnicos para a recuperação da informação, logo, acaba incluindo como ferramentas soluções livres que podem ser acopladas em softwares de bibliotecas digitais mas que não são soluções completas de bibliotecas digitais. Dessa forma, acabamos não podendo utilizar os mesmos critérios sugeridos pelo trabalho e, eventualmente, realizar comparações com seus resultados.

O trabalho de Sunye (2010) chama atenção para os aspectos de segurança para a grande quantidade de informação e necessidades de preservação das iniciativas de bibliotecas digitais. Esses elementos também apareceram nos artigos que apresentamos a seguir e, portanto, foram levados em consideração como critérios técnicos para comparação de softwares para bibliotecas digitais.

Já na discussão sobre softwares livres e seu potencial de aplicação para bibliotecas digitais, ressaltando a importância do modelo para a área, encontramos os trabalhos de Damásio e Ribeiro (2006) e Moreiro González (2006). Em síntese, as pesquisas apontam a viabilidade desse modelo para as bibliotecas digitais e sua potencial capacidade de interoperabilidade com outros sistemas de informação que atendem a padrões livres na web, facilitando com que essas aplicações possam 
integrar iniciativas de agregação da informação, como bibliotecas federadas, por exemplo.

Apesar da importância das referencias apresentadas, sobretudo como indícios da importância do tema para a área da informação, ainda faltam pesquisas de cunho aplicado, que não apresentem os softwares utilizados e como foram implementados, mas que também permitam identificarmos quais os critérios devem ser considerados para comparar essas aplicações e que ajudem a gestores e pesquisadores tomarem melhores decisões quando da escolha da solução que utilizarão em seus projetos.

\section{A pesquisa sobre critérios de avaliação de bibliotecas digitais}

Uma das pesquisas que consideramos mais relevante e que forneceu importantes elementos para nosso trabalho foi o relatório da UNESCO intitulado "Institutional Repository Software Comparison" escrito por Bankler e Gleason (2014). O relatório se propõe a ser um guia para a escolha de softwares de repositórios institucionais fazendo a comparação entre as 05 ferramentas que consideram como as plataformas mais adotadas por repositórios, sendo elas a Digital Commons, Dspace, Eprints, Fedora e Islandora. Dentre essas, apenas a Digital Commons não é um software livre e, portanto, não foi levada em consideração para nossa pesquisa. O estudo apresenta a comparação entre os softwares a partir de 11 categorias que "ajudam os bibliotecários a identificar as funcionalidades mais importantes para a escolha de um programa de repositório institucional para suas instituições”. As dimensões são: infraestrutura (envolve condições de instalação, hospedagem e suporte técnico), interface e design (envolve características de customização da interface e adaptação a dispositivos móveis), organização do conteúdo e controle (envolve formas de suportar a produção de conteúdo, controle de acesso e estrutura do repositório), descoberta de conteúdo (envolve funcionalidades de busca), ferramentas de publicação (envolve funcionalidades de revisão por pares, edição de metadados e fluxos de publicação), relatórios (envolve indicadores, gráficos e relatórios automatizados), multimídia (envolve suporte a diferentes tipos de mídias), funcionalidades sociais e notificação (envolve integração com redes e mídias sociais e formas de notificação de ações da ferramenta), interoperabilidade (envolve funcionalidades de integração com outras ferramentas, protocolos e serviços), autenticação (envolve formas de validar a identidade dos usuários), acessibilidade (envolve funcionalidades voltadas para usuários com necessidades especiais) e, por fim, preservação (envolve 
funcionalidades de preservação e manutenção do conteúdo do repositório). O estudo segue apresentando os resultados de avaliação de cada ferramenta mostrando as funcionalidades dentro de cada uma das 11 categorias e apenas indicando se a respectiva ferramenta possui ou não cada funcionalidade. Não faz uma avaliação final indicando alguma ferramenta preferencial, apenas evidenciando a diversidade entre elas. Vale ressaltar que é o único estudo encontrado que ressalta funcionalidades sociais e notificação como uma dimensão importante a ser considerada.

O artigo de Patel e outros (2014), intitulado "Digital library software Dspace and Greenstone3: a study of features and comparative analysis", compara apenas dois softwares livres e foca apenas em características técnicas computacionais das ferramentas. O artigo foca em discutir os pré-requisitos técnicos de cada ferramenta, a compatibilidade com que tipos de gerenciadores de banco de dados, sistemas operacionais e apresenta uma lista bastante genérica de funcionalidades da ferramenta, tais como se possui ou não serviço de catálogo, suporte a multimídia e serviços de busca. A contribuição desse estudo se encontra em ressaltar a importância do ambiente de instalação da ferramenta e seus pré-requisitos técnicos.

O artigo publicado por Kumar e Raghunadha (2013), intitulado “Analytical study on knowledge about open source software in technological institutional LIS professionals”, apresenta um estudo qualitativo por meio de questionário entrevistando 50 bibliotecários na Índia sobre sua opinião em relação aos softwares que utilizam para a formação de bibliotecas digitais. A pesquisa reporta os seguintes softwares citados pelos entrevistados para automação de bibliotecas, Koha, ABCD, NewGenLib, Evergreen, PhpMyLibrary, OpenBiblio, Avanti, e os seguintes softwares para bibliotecas digitais, Dspace, Greenstone, E-prints e Fedora. A pesquisa avalia 15 dimensões analíticas, sem no entanto explicitar detalhadamente o significado de cada dimensão: se o software atende as demandas da biblioteca, sua qualidade (a pesquisa não explicita o que considera como qualidade), número de funcionalidades e funções, treinamento da equipe e estrutura de suporte técnico, sistema operacional, requisitos de hardware, módulos disponíveis (esse critério nos pareceu redundante com o número de funcionalidades e funções), interface com usuário, design, conformidade com padrões internacionais (MARC, Z39.50, ISO-2709, etc.), escalabilidade (o potencial que a ferramenta tem para atender à demanda crescente de acesso e número de usuários), customização pelo usuário, relatórios, níveis de segurança e possibilidades de migração e transferência de dados. $O$ artigo não apresenta uma 
síntese da comparação entre as ferramentas de bibliotecas digitais e nem mesmo mostra detalhadamente os resultados de cada ferramenta para os critérios escolhidos para análise.

O artigo publicado por Randhawa (2012), intitulado “Open Source Software for Creation of Digital Library: a comparative study of Greenstone Digital Library Software \& Dspace”, apresenta uma lista de 08 critérios bastante técnicos de comparação das ferramentas. São eles: sistema operacional de compatibilidade, tipo de licença, línguas suportadas na interface com usuário, softwares que são pré-requisitos para instalar cada ferramenta, padrões de metadados suportados, protocolos de interoperabilidade suportados, formas de suporte técnico oferecidas e formatos de arquivos suportados. O estudo apresenta uma discussão detalhada sobre os resultados de cada ferramenta por meio desses critérios, destacando algumas vantagens e desvantagens de cada uma delas, sem concluir indicando a diferença qualitativa geral entre elas.

O artigo publicado por Tramboo e outros (2012), intitulado “A study on the Open Source Digital Library Software's: special reference to Dspace, Eprints and Greenstone”, faz uma apresentação detalhada das principais características técnicas de cada uma das 03 ferramentas que estuda, destacando os modelos de funcionamento e fluxo de informação em cada uma delas. Utiliza para isso referência aos manuais técnicos das ferramentas, bem como infográficos de cada uma delas. A partir dessa apresentação detalhada, destaca 19 critérios de comparação entre as ferramentas. São eles: custo de atualização, forma de identificação única dos recursos digitais, disponibilidade de OAI-PMH, tipos de itens suportados, formatos de metadados suportados, funcionalidades de interface com usuário, apresentação de amostra de recursos multimídia, recursos de busca, opções de navegação pelos recursos digitais, disponibilização de feeds (estilo RSS e ATOM), formas de autenticação do usuário, formas de relatórios estatísticos, sistemas operacionais suportados, bancos de dados suportados, linguagem de programação suportadas, tipos de servidores web suportados, softwares associados necessários para funcionamento, protocolos de interoperabilidade suportados, tipo de licença e disponibilidade de serviços de suporte e consultoria. No artigo, os resultados são apresentados para cada ferramenta segundo os critérios listados, não realizando uma avaliação qualitativa, apenas listando a presença ou não desses critérios e listando funcionalidades e itens disponíveis nos critérios pertinentes. Também não conclui indicando a diferença qualitativa entre as ferramentas.

O artigo publicado por Lihitkar e Lihitkar (2012), intitulado “Open Source Software for 
Developing Digital Library: comparative study”, compara 10 softwares para bibliotecas digitais, sendo eles: GSDL, Dspace, Ganesha, Fedora, E-prints, Invenio, Dienst, VuDL, XTF e NewGenLib. É o estudo que comparou mais ferramentas em formato software livre que encontramos. O artigo utiliza 05 critérios de comparação entre as ferramentas e 05 critérios quantitativos que somam o desempenho nos critérios de comparação. São eles: o tipo de licença de software, os softwares que são pré-requisitos para instalação, o número total de softwares de pré-requisitos, os sistemas operacionais suportados, as línguas suportadas na interface com usuário, o número total de línguas suportadas, as funcionalidades disponíveis em cada ferramenta de uma lista de 10 funcionalidades indicadas, o número total de funcionalidades disponíveis em cada ferramenta, parâmetros de busca disponíveis e o número total de parâmetros de busca disponíveis em cada ferramenta. $\mathrm{O}$ artigo apresenta uma tabela síntese quantitativa que compara as 10 ferramentas nos 05 critérios analisados. A tabela compara apenas o número absoluto de funcionalidades em cada critério e apresenta uma somatória ao final. Segundo os resultados do artigo, as 03 ferramentas de melhor resultado são GSDL, VuDL e Dspace/E-prints empatados na terceira colocação.

Por fim, o artigo de Goh e outros (2006), intitulado “A checklist for evaluating open source digital library software”, foi considerado por nós, juntamente com o primeiro estudo da UNESCO apresentado, como um dos que mais contribuiu para nossa pesquisa. $\mathrm{O}$ artigo apresenta uma revisão bibliográfica detalhada sobre bibliotecas digitais e software livre, escolhendo para análise 04 ferramentas: CDSware, Eprints, Greenstone e Fedora. São escolhidas 05 dimensões analíticas para serem comparadas, sendo que dentro de cada uma delas são definidos critérios de avaliação. As dimensões são gerenciamento de conteúdo (relacionado a como o conteúdo é criado, submetido, revisado, organizado e versionado), interface do usuário (cobre critérios sobre como a interface pode ser flexível e customizada pelos usuários), administração do usuário (cobre critérios sobre as funcionalidades necessárias para administrar os usuários na biblioteca digital), administração do sistema (são critérios relacionados a aquisição de conteúdo automático, geração automática de metadados, reconhecimento de entidades e classificação e indexação automática de objetos) e outras funcionalidades (funcionalidades de interoperabilidade, suporte a línguas, padrões de metadados, tipos de arquivos suportados, entre outras). O artigo apresenta no apêndice um questionário detalhado com uma proposta de pontuação para cada dimensão descrita acima e de cada critério dentro de cada dimensão. O questionário evidencia as funcionalidades e características que são consideradas mais importantes para os pesquisadores dentro de cada dimensão analítica. 
A soma da pontuação de cada dimensão resulta no valor 100 sendo que a soma dos critérios dentro de cada dimensão soma no total apenas 10 pontos. O questionário é aplicado pelos próprios pesquisadores e chegam ao resultado final classificando as 04 ferramentas, por ordem de importância, na sequência CDSware, Greenstone, Fedora e, por fim, o Eprints.

Dos métodos de pesquisa utilizados para comparação das ferramentas, queremos aqui destacar a metodologia utilizada por Goh e outros (2006), por seu nível de detalhamento e sistematização dos critérios, permitindo resultados empíricos que nos pareceram mais consistentes na construção de um método analítico que se propõe a apresentar resultados conclusivos que procurem evidenciar a posição de cada ferramenta em uma escala representativa, facilitando a tomada de decisão de profissionais com base nos critérios apresentados.

Numa avaliação geral, os estudos apresentados se mostraram muito focados em características mais técnicas computacionais das ferramentas, sendo que apenas o estudo da UNESCO apresentou dimensões analíticas que destacam a questão da preservação de objetos digitais e relacionamento com redes sociais como critérios que devem ser levados em consideração para a análise de bibliotecas digitais. Esse resultado denota que há um importante trabalho ainda a ser construído na incorporação nos critérios de avaliação de ferramentas de bibliotecas digitais de funcionalidades que estão mais relacionadas a gestão dos serviços de informação e a modelagem de fluxos informacionais.

Um dos passos importantes que consideramos para o avanço da pesquisa nesse tema é a própria construção de um vocabulário mais abrangente para a categorização dos critérios de avaliação das ferramentas de bibliotecas digitais. Como podemos notar nos artigos apresentados acima, temos uma grande variedade de critérios que, apesar de mais focados em aspectos técnicos, não são fáceis de serem agrupados em categorias genéricas que permitam facilmente integrar esses critérios e identificar dimensões analíticas que devemos levar em consideração.

O que faremos a seguir, como proposta de um vocabulário que facilite explicitar essas dimensões analíticas, é olharmos com maior atenção para as dimensões que a arquitetura da informação leva em consideração para pensar a respeito de sistemas de informação. 


\section{Arquitetura da informação e uma visão de dimensões analíticas para sistemas de informação}

Existem várias definições para o termo "arquitetura da informação". Para McGee e Prusak (1994, p. 129) seu objetivo é "criar um mapa abrangente dos dados organizacionais e em seguida construir um sistema baseado nesse mapa". Segundo Toms e Blades (1999, p. 2471, apud CAMARGO, 2004, p. 30):

A arquitetura da informação representa a maneira pela qual a informação é categorizada e classificada, armazenada e acessada e exibida determinando, assim, as formas como o usuário poderá encontrar a informação que necessita. A arquitetura da informação é a planta, o mapa para a organização virtual da informação, incluindo as formas como o usuário navegará e acessará a informação.

Segundo Pinheiro e Ferrez (2014), a arquitetura da informação consiste em realizar "o planejamento, organização e etiquetagem de sítios web, intranets, comunidades em linha e programas de computador de forma a possibilitar aos usuários localizar e usar a informação".

Ao que aqui apresentamos, a arquitetura da informação parece fornecer um vocabulário que explicita qualidades comuns para pensar sistemas de informação em diferentes áreas do conhecimentos e focos de aplicação.

Além disso, já a tempos a pesquisa na área da Ciência da Informação vem explicitando a importância da arquitetura como um paradigma na formação de bibliotecários e uma importante contribuição na geração de novos serviços de informação, dentre os quais podemos aqui destacar as bibliotecas digitais. Espantoso (2000) já aponta isso, conforme vemos aqui suas considerações sobre a formação do bibliotecário:

As novas tecnologias de informação surgem como um elemento central na evolução da ciência e da cultura. O profissional formado em biblioteconomia precisa adaptar-se à utilização destes novos serviços. Precisa conhecer melhor este campo, para utilizá-las como importante ferramenta de disseminação da informação. Verificamos que a contribuição que o profissional formado na área de biblioteconomia na Arquitetura de Informação gravita em torno do conhecimento de princípios de seleção, acesso a informação, conhecimento de busca, catalogação e classificação.

Entendemos aqui que a arquitetura da informação apresenta uma forma de organizar as

1 TOMS, E. G.; BLADES, R. L. Information architecture and web site design. Feliciter, v.45, n.4, 1999. Disponível em: http://www.cla.ca/feliceter/45-4/column2.htm.

InCID: R. Ci. Inf. e Doc., Ribeirão Preto, v. 8, n. 1, p. 100-121, mar./ago. 2017. 
funções de exercício de um profissional da informação na sua relação com um sistema de informação, indicando um possível vocabulário teórico que podemos nos servir como apoio a sistematização de critérios de avaliação para ferramentas de bibliotecas digitais e, para além disso, de sistemas de informação de uma forma geral.

Como é ilustrado na figura 01, a arquitetura da informação é um campo interdisciplinar que interage com várias outras disciplinas tais como usabilidade, design de interação, experiência de usuário, entre outros. Dessa forma, parece unificar em torno de sua proposta teórica diversas abordagens que devem ser levadas em consideração quando da análise do fenômeno de se pensar e produzir um sistema de informação.

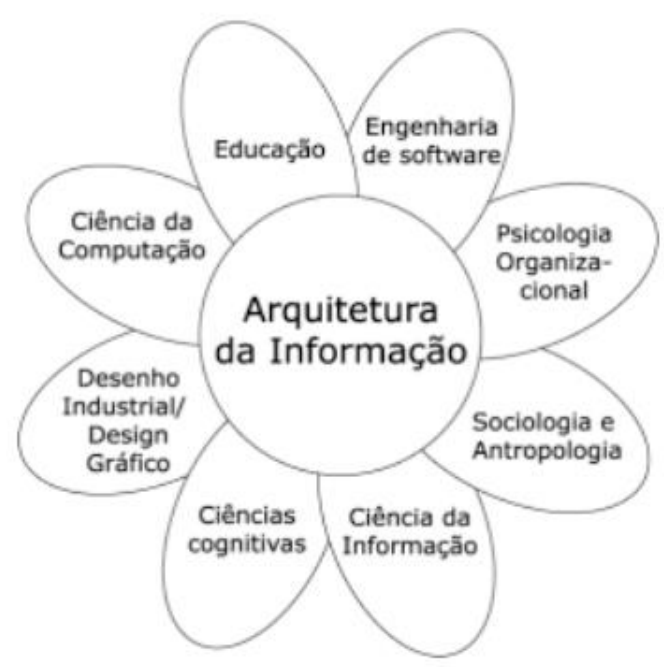

Figura 01 - Relações da arquitetura da informação com outras disciplinas Fonte: Dillon, 20012 apud Agner e Silva, 2003.

No campo do design, a arquitetura da informação é tratada por alguns autores quase como sinônimo de design da informação, entretanto, é possível perceber na literatura que o design de informação aborda com mais frequência aspectos estéticos e de apresentação da informação, enquanto a arquitetura da informação geralmente trata das estruturas ou dos esquemas de organização, representação e recuperação da informação.

Na definição de Rosenfeld e Morville (2006), a arquitetura da informação pode ser descrita e organizada por 04 sistemas ou componentes: sistemas de navegação, que provê maneiras para o

2 DILLON, A. If this is information architecture, i need a plumber! Bulletin of the American Society for Science and Technology, v. 28, n. 1, oct./nov. 2001. Disponível em: <http://www.asis.org/Bulletin/Oct-01/dillon.html>. Acesso em: 2003.

InCID: R. Ci. Inf. e Doc., Ribeirão Preto, v. 8, n. 1, p. 100-121, mar./ago. 2017. 
usuário navegar, filtrar e encontrar uma informação em um site; sistemas de busca, que permite você encontrar algo através da simples pesquisa por palavra-chave ou busca avançada; sistemas de rotulagem, que envolve a descrição ou representação de conteúdo do site; sistemas de organização, como o conteúdo é categorizado, por exemplo através de assuntos ou cronologicamente. O sistema de organização está dividido em esquemas de organização e estruturas de organização. Os detalhes dos sistemas são apresentados na figura 02.

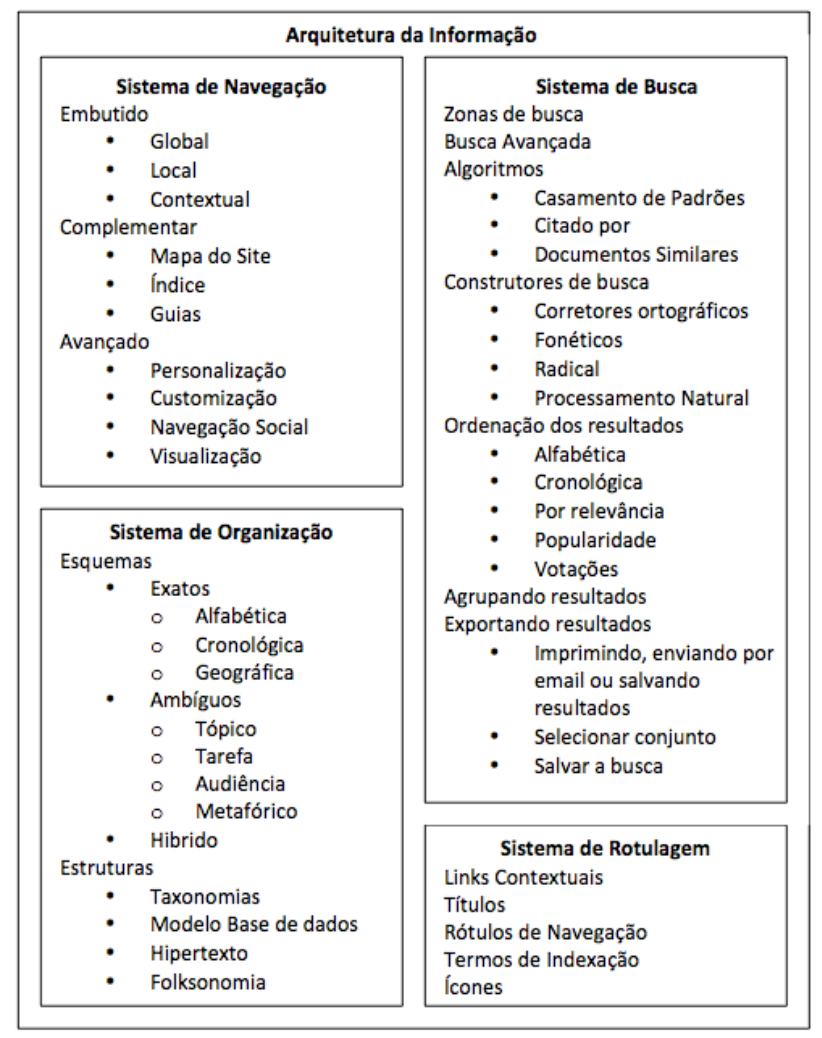

Figura 02 - Componentes da Arquitetura da Informação

Fonte: Elaborado pelos autores

Temos aqui, portanto, uma proposta teórica que organiza as funções de gestão e funções operacionais que são relacionadas a sistemas de informação em dimensões analíticas que sintetizam e facilitam agrupar essas funções. Entendemos aqui que esse é um importante ponto de partida na proposição de categorias gerais para a organização de critérios de avaliação para ferramentas de bibliotecas digitais, o foco da presente pesquisa.

Apresentamos, a seguir, como aplicamos as ideias aqui apresentadas da arquitetura da informação na construção dessas dimensões analíticas para os critérios de nosso interesse. 


\section{Proposta de organização de critérios e dimensões de avaliação}

Os critérios apresentados nos estudos levantados na revisão de literatura, foram reunidos para compor um conjunto de critérios para avaliação de ferramentas de bibliotecas. O grande número de critérios tornou a lista bem extensa, além de outros que incluímos por interesse de nossa própria pesquisa e por considerarmos serem elementos importantes que deveriam ser levados em consideração. Como apresentamos na seção anterior, para a organização inicial do modelo de critérios foi adotado o modelo de arquitetura de informação, proposto por Rosenfeld e Morville (2006) e ilustrado na figura 02. Dessa forma, os critérios relacionados com os sistemas de busca, navegação, rotulagem ou organização foram distribuídos e classificados conforme esse modelo. Apresentamos o resultado na figura 03, a seguir.

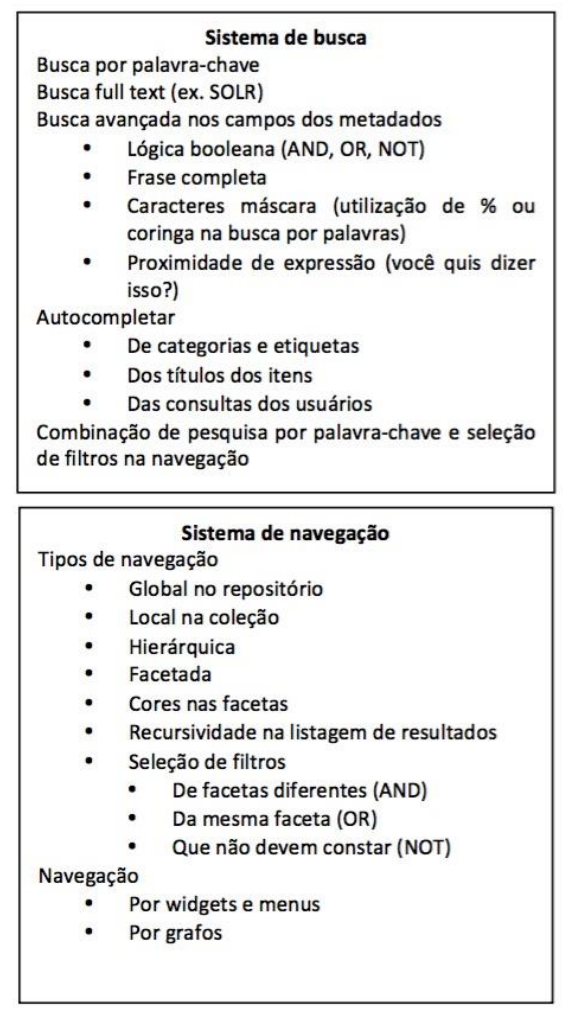

\begin{tabular}{|c|}
\hline $\begin{array}{l}\text { Sistema de organização } \\
\text { Tipos de organização dos resultados } \\
\text { - Por data de publicação ou modificação } \\
\text { - Pelo título ornado alfabeticamente } \\
\text { - Por popularidade } \\
\text { - Por votações } \\
\text { Sistema de organização do conhecimento } \\
\text { - Taxonomia } \\
\text { - Facetas } \\
\text { - } \quad \text { Tesauros e Ontologias } \\
\text { - Relacionamentos } \\
\text { - Herança } \\
\text { - Propriedade inversa e simétrica } \\
\text { - Cardinalidade } \\
\text { Metadados } \\
\text { - Definição de esquema de metadados } \\
\text { - } \text { Importaçãa de esquema de metadados via } \\
\text { url, arquivo (mds, xml) }\end{array}$ \\
\hline $\begin{array}{l}\text { Sistema de rotulagem e indexação } \\
\text { Seleção de termos em taxonomia } \\
\text { Digitação livre de etiquetas } \\
\text { Autocompletar de categorias e etiquetas } \\
\text { Drag n Drop } \\
\text { Tipos de campos do formulário de submissão } \\
\text { Configurar valores padrão para elementos de } \\
\text { metadados } \\
\text { Suporta caracteres UNICODE para conjunto de } \\
\text { caracteres de metadados }\end{array}$ \\
\hline
\end{tabular}

Figura 03 - Critérios de avaliação classificados segundo a arquitetura da informação Fonte: Resultados da pesquisa

Quase a metade dos critérios que identificamos e propusemos foram alocados dentro do que propõe a arquitetura da informação. Entretanto, haviam outros critérios que desejamos incluir e que não se adaptaram de forma imediata nos 04 sistemas acima propostos. Proveniente das leituras sobre as funções e modelos de bibliotecas e repositórios digital conforme apresentado neste artigo, 


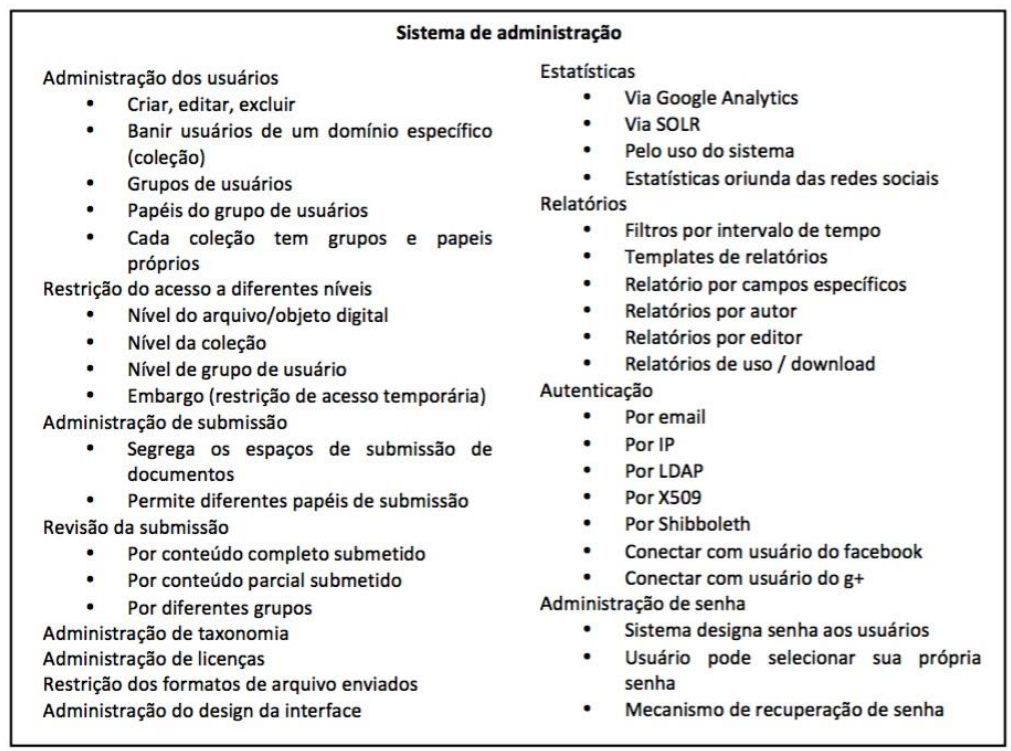

Figura 05 - Critérios referentes ao sistema de administração

Fonte: Resultados da pesquisa

O sistema de administração também inclui requisitos sobre controle do conteúdo, restrição de acesso, submissão, taxonomias, licenças, formato de arquivo, design, estatísticas, relatórios, autenticação e senhas. Isso mostra exigência de o sistema ter uma grande flexibilidade e capacidade de customização para servir em diferentes cenários de uso, com públicos e área do conhecimento diversificada.

Os critérios referentes a funcionalidades sociais e notificação, conforme proposto pelo estudo da UNESCO, deram origem ao próximo sistema. No sistema de colaboração e interação social, apresentado na figura 06, procurou-se incluir requisitos que estimulam o engajamento da comunidade de usuários na produção, descrição e organização do conteúdo, propondo, de certa maneira, novas possibilidades de explorar formas de organização de processo informacional, ativando inteligências e incluindo a possibilidade de usuários atuarem em etapas que tradicionalmente estão destinadas apenas a profissionais da informação. Entendemos e afirmamos aqui com nossa pesquisa que um critério de qualidade de uma ferramenta de biblioteca digital é suportar com funcionalidades a possibilidade de ativar a inteligência coletiva de seus usuários na curadoria de conteúdo. 


\begin{tabular}{|ll|}
\hline \multicolumn{2}{|c|}{ Sistema de Colaboracão e Interacão social } \\
Workflow de aprovação de pertinência do item & Dar voto em item de terceiros \\
Workflow de aprovação de metadados de item & Múltiplas votações por coleção \\
Workflow de aprovação por votação de usuários & Compartilhar votação em facebook \\
Workflow de aprovação por pares & Compartilhar item em redes sociais \\
Configuração de ação pré-aprovada (wiki) & Compartilhar coleção em redes sociais \\
Customização de workflow de aprovação de item & Comentários \\
Customização das etapas do workflow de & Notificações \\
submissão de uma coleção & Engajamento de usuários \\
Adicionar coleção em comunidade de terceiros & Gamificação (karma) \\
Remover (denunciar) coleção de terceiros & Compartilhar item em outras coleções \\
Adicionar item em coleção de terceiros & Buscas realizadas salvas \\
Remover (denunciar) item de terceiros & Filtro de Proxy \\
Adicionar classificação em itens de terceiros & Mensagem privadas entre usuários dentro do \\
Editar classificação em itens de terceiros & sistema de repositorio \\
Excluir classificação em itens de terceiros & Fórum de usuários \\
Adicionar categoria em coleção de terceiros & Grupos de usuários \\
Editar categoria em coleção de terceiros & Suporte à submissão \\
Excluir categoria em coleção de terceiros & email de notificação para usuários \\
Seguir & email de notificação \\
Favoritos (bookmark) & administrador \\
\hline
\end{tabular}

Figura 06 - Critérios referentes ao sistema de colaboração e interação social

Fonte: Resultados da pesquisa

O próximo sistema apresentado reúne requisitos de questões externas ao sistema de informação, mas que consideramos de grande importância para adoção como o suporte e manutenção, documentação, listas de email, perguntas e respostas frequentes, fórum, FAQ, sistemas de helpdesk e gestão de falhas, tendo alguns desses critérios sido utilizados pelos estudos de referência que apresentamos acima. Chamamos a esse sistema de suporte e manutenção e apresentamos seus critérios na figura 07, a seguir.

\begin{tabular}{|lc|}
\hline & Sistema de Suporte e Manutenção \\
Documentação e manuais & Bug tracker \\
Lista de email de apoio & Espaço de requisição de novas funcionalidades \\
Fórum de discussão & Suporte help desk \\
FAQ - dúvidas mais comuns & \\
\hline
\end{tabular}

Figura 07 - Critérios referentes ao sistema de suporte e manutenção

Fonte: Resultados da pesquisa

O último grupo foi denominado sistema de características gerais no qual foram agrupados os requisitos que são intrínsecos ao ambiente do sistema de informação tais como: arquitetura de servidores, banco de dados, linguagens de programação, design, licença do software, visualizadores, línguas, atualização, geolocalização e cache. Os critérios são apresentados na figura 08 , a seguir. 


\begin{tabular}{|ll|}
\hline \multicolumn{2}{|c|}{ Características Gerais } \\
Tem hospedagem externa & Acessibilidade - VPAT \\
Permite instalação local & Acessibilidade - WCAG \\
Tem sistema atualização automática & Acessibilidade - Section 508 \\
Grau de usabilidade & Suporta múltiplas línguas na interface \\
Tem design responsivo (mobile) & Padrões de empacotamento de metadados mais \\
Tem código aberto & comuns, o METS e o MPEG-21 \\
Visualizador de pdf na visualização do objeto & Cache \\
Visualizador de video na visualização do objeto & Permite home page para cada coleção \\
Geolocalização & Permite múltiplas coleçães \\
Conversão de textos completos para PDF & Pode ser enviados arquivos compactados \\
SEO & Listas de email de publicação \\
Rede de repositórios & \\
\hline
\end{tabular}

Figura 08 - Critérios referentes ao sistema de características gerais

Fonte: Resultados da pesquisa

O diagrama na figura 09 ilustra em alto nível a proposta de um modelo de dimensões analíticas para organizar os critérios para avaliação de bibliotecas digitais. O modelo tem 10 categorias fundamentais para organização dos critérios.

\begin{tabular}{|c|c|c|c|c|}
\hline $\begin{array}{c}\text { Sistema de } \\
\text { navegação }\end{array}$ & $\begin{array}{c}\text { Sistema de } \\
\text { organização }\end{array}$ & $\begin{array}{c}\text { Sistema de } \\
\text { administração }\end{array}$ & $\begin{array}{c}\text { Sistema de } \\
\text { preservação } \\
\text { digital }\end{array}$ & $\begin{array}{c}\text { Suporte e } \\
\text { manutenção }\end{array}$ \\
\hline $\begin{array}{c}\text { Sistema de } \\
\text { busca }\end{array}$ & $\begin{array}{c}\text { Sistema de } \\
\text { rotulagem }\end{array}$ & $\begin{array}{c}\text { Sistema de } \\
\text { colaboração e } \\
\text { interação social }\end{array}$ & $\begin{array}{c}\text { Sistema de } \\
\text { interoperabilidade }\end{array}$ & $\begin{array}{c}\text { Características } \\
\text { gerais }\end{array}$ \\
\hline
\end{tabular}

Figura 9 - Organização do modelo de critérios com 10 categorias fundamentais

Fonte: Resultados da pesquisa

O modelo com a descrição do significado de cada critério detalhado pode ser encontrado em Deus, Silva e Martins (2015). 


\section{Conclusão}

Apresentamos ao longo deste artigo um grande conjunto de critérios de avaliação de ferramentas de bibliotecas digitais e produzimos uma síntese desses critérios em torno de 10 dimensões analíticas, sendo elas inspiradas na arquitetura da informação e no agrupamento em novas dimensões que procuram expandir as definições dessa área e se tornarem mais aplicadas ao contexto específico das bibliotecas digitais. Concluímos esse trabalho com uma listagem extensa de critérios e com a proposta de um modelo que sabemos ser trabalhoso para aplicação na comparação de sistemas.

No entanto, entendemos que a possibilidade de identificar esses critérios e sistematizá-los em dimensões analíticas torna visível e dá consistência a uma visão global das bibliotecas digitais, permitindo expandir o conhecimento que temos dessas ferramentas e colocar em análise diversas dimensões que explicitam funcionalidades e serviços que a pesquisa na área tem apontado como desejáveis e relevantes.

É em torno do esforço de dar essa visibilidade que esse trabalho de pesquisa se orientou e constrói um modelo de requisitos que pode ser utilizado de forma adaptativa, ou seja, não esperamos que todos critérios estejam presentes em todos os sistemas e tampouco imaginamos que os profissionais de informação deveriam considerar todos esses critérios para a escolha de suas ferramentas. O que esperamos é que os profissionais possam ter acesso e, uma vez conhecendo o todo, tenham condições de escolher os critérios que atendam melhor suas necessidades e avaliar sistemas de informação que tenham melhor desempenho nesses critérios, fazendo escolhas e tomando decisões melhor informados e amparados em um repertório analítico mais consistente. Entendemos que a arquitetura da informação forneceu importante vocabulário para a categorização dessas dimensões, sendo uma área importante e reconhecida por profissionais da informação, facilitando em potencial o entendimento e a relevância dessas categorias.

Recomendamos, a título ainda de reflexão inicial, que esse modelo de critérios poderia ser aplicado de duas maneiras imediatas. A primeira seria pela simples identificação da presença de cada critério em cada ferramenta em comparação, ou seja, realizar um estudo comparativo que busca investigar se uma determinada funcionalidade se encontra naquela ferramenta sem ainda levar em consideração as possíveis diferenças de implementação que essas funcionalidades 
poderiam ter entre diferentes sistemas. A segunda, já mais complexa e elaborada, não apenas identificaria a presença desse critério como também poderia avaliar a qualidade da implementação segundo algum critério comparativo como, por exemplo, o grau de facilidade de uso por um usuário. Para ambos os casos, sugerimos a criação de questionários que poderiam atribuir valores numéricos para cada critério conforme o interesse específico de uma pesquisa, facilitando dessa maneira chegar a resultados numéricos que facilitem a comparação exata das ferramentas. A flexibilidade de modificar os valores numéricos para cada critério torna o método flexível para representar diferentes interesses e valorar de forma mais alta ou mais baixa diferentes critérios que são relevantes para as especificidades de cada projeto.

Por fim, pretendemos avançar em nossa pesquisa em duas direções específicas. A primeira consiste de aplicar o presente modelo de critérios na avaliação dos principais softwares livres identificados nesta pesquisa na área de bibliotecas digitais. Entendemos que esse primeiro resultado de aplicação pode ampliar de forma significativa o conhecimento que temos dessas ferramentas, suas potências, suas deficiências e características que talvez não tenhamos ainda conhecimento e nos permitam expandir em novas formas de uso e experimentação. A segunda tem relação com o uso desses resultados para identificar quais seriam os critérios mais importantes na customização de uma ferramenta de biblioteca digital voltada para ampliar experiências com funcionalidades de colaboração social e interação. Entendemos que essa é ainda uma área muita nova na pesquisa sobre bibliotecas digitais e que experimentar modelos que nos permitam propor novos serviços e possibilidades em torno de bibliotecas digitais com características mais sociais nos permitem avançar nosso conhecimento na área. 


\section{Referências}

AGNER, L.; SILVA, F. L. C. M. Uma introdução à arquitetura da informação: conceitos e usabilidade. In: CONGRESSO INTERNACIONAL DE PESQUISA EM DESIGN, 2. Artigo. Rio de Janeiro, 2003.

BANKIER, J. G., GLEASON, K. Institutional repository software comparison. United Nations Educational, Scientific and Cultural Organizations. France. 2014. 16 p.

CAMARGO, L. S. A. Arquitetura da Informação para biblioteca digital personalizável. 2004. 143 f. Dissertação (Mestrado em Ciência da Informação) - Faculdade de Filosofia e Ciências, Universidade Estadual Paulista, Marília, 2004.

DAMÁSIO, E.; RIBEIRO, C. E. N. Software livre para bibliotecas, sua importância e utilização: o caso Gnuteca. Revista Digital de Biblioteconomia \& Ciência da Informação, v. 4, n. 1, p. 70-86, 2006. Disponível em: <http://www.brapci.ufpr.br/brapci/v/a/7471>. Acesso em: 19 mar. 2017.

DEUS, W. J., SILVA, M. F., MARTINS, D. L. Definição dos critérios de avaliação de ferramentas de bibliotecas digitais. Relatório interno do Laboratório de Políticas Públicas Participativas. Faculdade de Informação e Comunicação. Universidade Federal de Goiás. 2015. Disponível em:

https://docs.google.com/document/d/170Nrooge0SJOGRv2uZRT73LxXoPvY7dHVhb8aLaiUkE . Acesso em 08/01/2016.

ESPANTOSO, J. J. P. O arquiteto da informação e o bibliotecário do futuro. Revista de Biblioteconomia de Brasília, Brasília, v. 23/24, n. 2. especial 1999/2000. p. 135-146.

GOH, D. H.-L. et al. A checklist for evaluating open source digital library. Online Information Review, v. 30, n. 4, p. 360-379, 2006.

KUMAR, K., RAGHUNADHA, R. T. Analytical study on knowledge about open source software in technological institutional LIS professionals. International Journal of Library and Information Science, v. 5, n. 11, p. 439-446, dec. 2013.

LIHITKAR, S. R., LIHITKAR, R. S. Open source software for developing digital library: comparative study. Journal of Library \& Information Technology, v. 32, n. 5, p. 393-400, sep. 2012.

MCGEE, J.; PRUSAK, L. Gerenciamento estratégico da informação: aumente a competitividade e a eficiência de sua empresa utilizando a informação como uma ferramenta estratégica. Rio de janeiro: Campus, 1994.

MINISTÉRIO DA CULTURA. Minc defende a criação de uma política nacional de acervos digitais. 2015. Disponível em: http://www.cultura.gov.br/o-dia-a-dia-da-cultura/lasset_publisher/waaE2360ves2/content/minc-defende-criacao-de-uma-politica-nacional-de- 
acervos-digitais/10883. Acesso em: 08 jan. 2016.

MOREIRO GONZÁLEZ, J. A. et al. Bibliotecas digitales y open source software. Informação \& Sociedade: Estudos, v. 16, n. 1, p. 13-21, 2006. Disponível em:

<http://www.brapci.ufpr.br/brapci/v/a/7644>. Acesso em: 19 mar. 2017.

MORENO, C. T. C. Sobre pontes: o imperativo da interdisciplinaridade no mundo das bibliotecas digitais. Revista USP, São Paulo, n. 80, p. 88-95, dez.2008/fev. 2009.

PATEL, D. B. et al. Digital library software Dspace and Greenstone3: a study of features and comparative analysis. E-Library Science Research Journal, v. 2, n. 6, p. 01-07, Apr. 2014.

PINHEIRO, L. V. R.; FERREZ, H. D. Tesauro Brasileiro de Ciência da Informação. IBICT, 2014.

PLASENCIA-SALGUEIRO, A.; BALLAGAS-FLORES, B. R. L. M. Análisis comparativo de herramientas de recuperación y análisis de información de acceso libre desde una concepción docente. Transinformação, Campinas, v. 26, n. 3, 2014. Disponível em: <http://www.brapci.ufpr.br/brapci/v/a/16302>. Acesso em: 19 mar. 2017.

RANDHAWA, S. Open source software for creation of digital library: a comparative study of Greenstone Digital Library Software \& Dspace. Indian Journal of Library and Information Science, v. 6, n. 3, p. 45-52, sept./dec. 2012.

ROSENFELD, L.; MORVILLE, P. Information architecture for the world wide web. O'Reilly Media, 2006.

SAYÃO, L. F. Afinal, o que é biblioteca digital? Revista USP, São Paulo, n. 80, p. 6-17, dez. 2008/fev. 2009.

SUNYE, M. Bibliotecas digitais e os desafios do arquivamento digital, uma visão da ciência da computação. Encontros Bibli: Revista Eletrônica de Biblioteconomia e Ciência da Informação, v. 15, n. 29, p. 01-32, 2010. Disponível em:

<http://www.brapci.ufpr.br/brapci/v/a/8871>. Acesso em: 19 mar. 2017.

TRAMBOO, S. et al. A study on the open source digital library software's: special reference to Dspace, Eprints and Greenstone. International Journal of Computer Applications, v. 59, n. 16, p. 01-09, dec. 2012. 